\title{
The Pragmatics of Indirect Reports and Slurring
}

\author{
Alessandro Capone
}

\begin{abstract}
According to Volosinov (1971) there is a tension between two indirect discourse practices; one in which the reported message's integrity is preserved and the boundaries between the main message and the embedded reported message are formally marked and one in which such boundaries are dissolved as the reporting context allows the reporting speaker to intrude to a greater extent and transform the message by stylistic interpolations. This tension is clearly resolved, in the context of my paper on indirect reports, through the recognition of pragmatic principles which assign default interpretations (according to which the boundaries between the reporting message and the reported message are clearly visible and the reported speaker's voice prevails at least within the embedded message), while allowing context to create priorities which override the default interpretations and make the otherwise costly violations of the pragmatic principles worthwhile thanks to the facilitation and subordination of the information flow to the exigencies of the embedding context (Of course, this tension is clearly instantiated in language (it is not only a theoretical problem). As a referee points out, we are focusing on a case in which two practices are in tension. The resolution of a tension between two different, possibly opposite, practices clearly depends on practical considerations leading the language users to prefer one to the other. Deviation from a practice that conforms to ideal principles of use must always involve a cost that needs to be offset by practical advantages. One of these advantages could be the facilitation of the recognition of a referent. Another possible advantage could be, as happens in many cases, the simultaneous utterance of a speech report and a criticism).
\end{abstract}

\footnotetext{
A. Capone $(\bowtie)$

University of Messina/Palermo, San Francesco P 10798051 Barcellona, Italy

e-mail: alessandro.capone@istruzione.it
} 


\section{Introduction}

The practice of indirect reporting involves a mixture of serious and non-serious use, as this practice, on the one hand, involves transformations in the sense of Goffman (1974), ${ }^{1}$ on the other hand it involves using language in the context of a serious activity, such as describing what another person said. The practice of indirect reporting is sensitive to contextual information and, thus, it goes without saying that the richer the cues and clues allowing speakers to interpret transformations (see Dascal and Weizman 1987), the more complex are the transformations involved in the indirect reports. And the more complex the transformations are, the greater the need for a decoupling principle along the lines of Clark and Gerrig (1990):

Speakers intend their addressees to recognize different aspects of their quotations as depictive, supportive, and annotative.

Mutatis mutandis, we can apply the Decoupling Principle to indirect reports:

Speakers intend their addressees to recognize different voices belonging to the indirect report and, in particular, to separate voices attributing them to the original source, the current speaker (the indirect reporter) or some other person involved in context. They also intend addressees to recognize supportive and annotative aspects.

To make the considerations above less cryptic, I note that supportive aspects are those which in one way or the other allow the speaker to make the indirect report. For example, the reporter may use English to report a Latin utterance. This use of English is clearly supportive and NOT depictive (of course, hearers should have pragmatic ways to decouple such aspects). Annotative aspects are those which are noted, without serving a principal purpose in the practice of reporting (for example I can note that the original speaker was giggling while using a certain word). Depictive aspects concern the words actually proffered.

I have now already departed to some extent from the standard practice to consider indirect and direct reports neatly differentiated. Clark and Gerrig themselves consider the two practices to be neatly separated, because quotation prevalently makes use of depictive aspects of language use while indirect reports make use of descriptions. Presumably, using Clark and Gerrig's terminology, there are other reasons for keeping the two practices distinct. Clark and Gerrig (p. 771) note that quotation involves both serious and non-serious language use. It involves serious language use in that the quoted item is syntactically an NP; it involves nonserious language use in that the quoted item is syntactically a sentence $(S)$ and, thus, depictive elements prevail if the item is considered a sentence. ${ }^{2}$ Presumably,

\footnotetext{
${ }^{1}$ For example, shifts from serious to non-serious or depictive uses.

2 Presumably, Clark and Gerrig seem to accept that an NP is presuppositional, thus expresses an extensional object; a sentence embedded in a verb of propositional attitude or in a quotative structure can express a non-extensional object. Simple cases that can illustrate what Clark and Gerrig have in mind could be the following: "I want that car" (or "I want the car"). Here it is plausible that the NP following 'want' identifies an extensional object and not ONLY an
} 
by Clark and Gerrig's standards, indirect reports should only involve serious uses of language, since only NPs are involved here, rather than sentences intended in their depictive sense. However, we all know that indirect reporting is very often a polyphonic practice where the hearer's main task is to separate voices attributing them to different actors. Even if we stay within Clark and Gerrig's terminology, it is universally recognized that there are what are often called 'mixed quotations', that is to say cases of indirect reports in which some segments are quoted. Mixed quotations are considered relatively rare cases-while the point of my discussion is that they should be considered as prototypical cases of indirect reports and that indirect reports in general should be modeled after mixed quotations (see Capone 2010a).

I have already said that indirect reports are interpreted in context. Here, however, the term 'context' is ambiguous, because, strictly speaking at least two types of context should be relevant to the interpretation of indirect reports: the context of utterance (of the original speaker) and the context of utterance (of the indirect reporter). There is often an interesting interplay between the two. We should note from the beginning that chronological considerations are important in ranking the two contexts and that the context of utterance (of the reporting speaker) is the departure point from which interpretation starts. It is often useful, therefore, to bear in mind what the purpose of the indirect report is or might be.

Indirect reports are cases in which you transmit knowledge of what another person said and what another person said is the only way or one of the ways in which you can gain knowledge about a certain situation or event $\underline{\mathbf{s}}$. The situation is clearly different from that of perception, where the only mediating elements are the perception system and certain a priori principles of knowledge. In indirect reports, the situation $\underline{\mathbf{s}}$ is transformed two times ${ }^{3}$ : once by the original speaker and then by

\footnotetext{
(Footnote 2 continued)

intentional one. There are cases where we might object to the equation of an NP with an extensional object, as in the case "John wants to sell his cello". Here 'His cello' could either escape the scope of the modal 'wants' or it could still be under its scope. Despite these controversial criteria, there are syntactic positions correlating with extensional/non-extensional, such as 'want NP', especially if the NP is definite. Anyway, I quite agree with a referee that the criteria by Clark and Gerrig are not uncontroversial.

3 The situation described by an indirect report is usually an utterance by an original speaker who, in his speech act, described or brought about a situation (in the case of a non-assertive speech act). A situation is a state or event with possible participants in it. When I say that a situation is transformed through an indirect report, I mean that the reporter uses NPs that are not neutral, but may express his/her point of view and, in particular, a critical attitude (for example if the reporter makes use of epithets). The situation may be transformed in another way, as the reporter may avoid using NPs actually used by the original speaker, but may use different NPs to make sure that the Hearer can identify the referent in question. I used the term 'transformations' but I could have used the term 'modifications'. However, 'transformations' refers to an operation effected linguistically and possibly in a systematic way. In fact, it might be predictable and therefore systematic that if the hearer cannot identify the referent through an NP used by the original speaker, the reporter must use a different NP, one that allows the hearer to identify the referent. Transformations are rather systematic practices. When you are confronted with an indirect report
} 
the reporting speaker. So, the task of the hearer is clearly an inferential task; how to delete possible transformations and how to get (back) to $\underline{\mathbf{s}}$ without the interference of possible transformations. This is clearly an inferential task requiring pragmatics. Now, if the hearer of the indirect report is interested in the indirect report mainly because it allows her to have access to $\underline{\mathbf{s}}$, the reporting speaker knows this and may very well take this into account in her treatment of the information concerning the original utterance. So we may grant that at least part of the transformations may be shaped by the desire to meet the interests of $\mathrm{H}$ in knowing about $\underline{\mathbf{s}}$. Other transformations may be independent of the interests of $\mathrm{H}$ or may conflict with it. Just to mention a case, consider the reporter who said: 'John said that the bus for Oxford is on the left when you get out of the airport'. It is crucial, in this interpretation process, that the perspective be the same. And that must be: passenger getting out of the airport. If the perspective adopted in the indirect report was different from that adopted in the original utterance, confusion would ensue. Thus we exclude that the perspective could be: relatives waiting for the passenger out of the airport. If, for some reason, the indirect reporter transformed the utterance without taking into consideration the hearer's interests, an uninterpretable utterance would result (or to be more correct an utterance providing misleading information would result). As upshot of this, the purpose of the indirect report must feature prominently among the factors to take into account in the interpretation as well as in the production of indirect reports. Let us consider, provisionally, the basic structural elements that go into an indirect report.

Context 1 (original speaker; original Hearer)

Context 2 (reporting speaker; reporting speaker's Hearer)

\section{Decoupling Principle}

Separate the original speaker's from the reported speaker's voice. Establish which portions of the text have a directly pictorial function. ${ }^{4}$

Separate those parts which have a supportive or an annotative function.

Purpose 1 (original speaker)

Purpose 2 (reporting speaker)

Purpose 3 (addressee).

\footnotetext{
(Footnote 3 continued)

that makes use of epithets (that bastard), you may be pretty sure that the speaker is using language in a critical way and thus a systematic effect on the hearer is the desire to know the difference between the NP used by the reporter and the one used by the original speaker. These transformations are systematic also in the sense that it might be possible to spot them and to go back to the original utterance via reflective processes.

${ }^{4}$ Perhaps the best example of the pictorial function is the following: John has SEEN Mary in the BATHROOM. There are cases, like the one above, in which language is used to express the form (boldface, for example) of an utterance. In this case we have a visual dimension, but sometimes we have an aural dimension, as in the case of a speaker who imitates the voice of another speaker (imitation) (or the style). Normally, however, by 'pictorial' Clark and Gerrig mean that a speaker depicts the actual words employed in a certain utterance.
} 
Point of view 1 (Original speaker)

Point of view 2 (reporting speaker)

Point of view 3 (addressee).

Now that the structural components of the practice of indirect reports are in place, we can expect that a theory of indirect reports could be built objectively on this basis, perhaps on the basis of recursive operations that take into account the basic components.

\section{Indirect reports as language games}

In my previous work on indirect reports I have focused on reports as language games (Capone 2010a, 2012). Language games are activities produced through speech in conformity to social rules determining what can count as what (in the speech situation). A language game is a strip of social activity (of social life) where language (speech acts) play an important role in the execution and decodification (and interpretation) of the activity. ${ }^{5}$ A language game is a form of life, the individual being able through it to participate in a social form of life (being integrated in a social dimension and coordinated through action with other members of the group). Now, while there may be differences between Goffman's terminology as used in the previous section and the terminology of language games, it is also clear that there is substantial overlap. Goffman presumably saw the continuum of social practices as segmented [or 'framed' (Goffman 1974)]. Each segment was to be recognizable as there had to be boundaries between outside and inside activities. An example of Goffmanian analysis that is well known is that of the lecture (Goffman 1981). The lecture is a bounded activity, which has its own rules. Participants know well and in advance how to behave in this segmented area, they know that there is little space for interruptions, they know that lectures have a forthcoming segment reserved for questions and answers (by the lecturer). Clearly, the lecture is also a language game, because it is structured, it has rules, it is part of societal activities, it is sufficiently differentiated from other language games. So, substantially, Goffman's theory of frames and forms of talk must coincide in broad lines with a theory of language games — or at least it must be possible to explore interconnections and overlapping territory.

But why should we want to deal with indirect reports-activities confined to small segments of interaction-in terms of language games, which are usually activities that unfold for some time and occur at some place which is substantially involved in the language game and even serves to characterize it (for example, court procedures)? And now my answer is that even if indirect reports are not normally really extended in time as language activities, they involve embeddings such as those described in the Introduction, and which we may illustrate schematically as in the following:

Indirect report C (indirect reporter)

5 In conformity with Wittgenstein's Philosophical Investigations. 
Original speaker $\mathrm{C}$ (original speaker)

Addressee C (addressee).

Although the language game is temporally limited, if we consider the dimension of the linguistic activity that unfolds in a temporal succession, the temporal embeddings obtained by reconstructing the original speaker's situation are potentially manifold and complex. Complexity is introduced when we see connection with other language games such as the following.

Consider a child game, which almost everyone practiced in childhood or adolescence:

There are, say, 20 boys (or girls) in a room. Each whispers to the next person in the line (or circle) what was whispered into his hear previously. The aim of the game is to show that, although, ideally, the initial and the last utterance have to be the same, the initial utterance is so transformed that the last utterance can hardly be heard to bear any meaningful relation to it.

This might be a game pointing to a practice which is quite standard in society and is based on reliable methods for transmitting and preserving information during the transmission process. The previous game dramatically illustrates the problems inherent in the game 'reporting information' or 'reporting an utterance'.

Consider another game such as the dumb-show.

A dumb-show was one of our favorite games in childhood. We practiced it, I presume, as a form of preparation in view of more serious or important societal language games. In a dumb-show you must depict information by avoiding words. You usually use gestures, even if you can point to words which happen to be written on a blackboard or on a poster. Now, since depicting occurs so heavily in direct reporting and, also in indirect reports, this is clearly a case in which we consider 'depicting' an important part of language games, a component which may be shared by different language games.

Another language game which is crucial for the understanding of indirect reports is a theatrical performance. In a theatrical performance we usually pretend, we are not using language in a serious way. An actor does not talk for herself, but on behalf of a character. This is more or less what happens in direct reports, but also what happens in indirect reports, if we consider them as polyphonic activities (see also the problematic case of mixed quotation in indirect reports).

Another case of language game that is deeply rooted in society is testimony in court. Here it might be important to be able to report what another person said on a certain occasion. This may well be an extreme case, where there is little freedom for transformations and where one needs to separate one's voice from that of the original speaker by formal markings. This practice diverges from the daily practice, to a great extent. Here a reporter may be asked by the prosecutor to reflect on the words used, to make an effort to separate her own voice from that of the original speaker. This practice may well involve a meta-representational component, as one is interested in the meanings as well, in the connotations as well as in the denotations. The reporter may well be turned into an analyst of her own speech. 
(Do you exactly mean that ...?). This is clearly a case where reporting is considered a meta-linguistic activity.

So, although it is true that indirect reports are small segments of talk or small strips of social behavior, they nevertheless have many features in common with other strips of behavior which we are less reluctant to call 'language games'. This may be enough to see that the connection between language games and indirect reports is well justified.

Dascal et al. consider that the notion of language game by Wittgenstein involves a shift from phenomenalism to physicalism, language games being primarily intended to create social reality. Can the language game of indirect reporting be so intended? If we follow Tannen (1989), indirect reports can, indeed, be considered as actions serving to construct social reality. An indirect report can have effects on deliberation, on action, in that it can present a piece of information that can be integrated into the argumentative structure of practical reasonings. Seen in this light, an indirect report can become a 'form of life' (Wittgenstein 1953).

Another feature of language games, according to Dascal et al. (1996) is that they are cooperative [they are constructed jointly by different speakers (or the speaker and the hearer)]. Can this be a characteristic of indirect reports (such as language games)? My reply in Capone (2012) was that the recognition of the role of the Hearer (or addressee) in the amount of transformations required in the practice of indirect reporting amounts to a recognition of the cooperative nature of indirect reports. Indirect reports-like other language games-involve an altruistic stance towards the addressee, which is instantiated in important linguistic choices that can be seen as transformations.

In Capone (2012) I specifically discussed indirect reports as language games, in the light of considerations by Dascal et al. (1996) on language games. Here I cannot expand that discussion, but I confine myself to extrapolating the most important points. Dascal et al. consider polyphony a specific language gamenow, while surely indirect reports are interesting also for other features, such as representational ones, it is clear that polyphony is a language game that is embedded in the practice of indirect reporting. The game also consists in the way clues and cues are utilized to separate the voices of the participants.

The language game 'polyphony' aims at the integration of different voices (expressing different points of view). Integration does not mean summation, but an interaction between two points of view such that one is, often, a commentary on the other. One of the problems we encounter in the description of indirect reports is, in fact, that an apparently single utterance contains different voices/points of view (thus it is polyphonic), apparently making it difficult for the hearer to separate them. However, the problem is not only how to separate points of view, but how to see the interaction between them. In an indirect report, we do not only have a neutral presentation of points of view, but normally the point of view of the indirect reporter is the main filter through which we hear other voices. Thus, it happens characteristically that there may be a relationship of criticism or otherwise affiliation between the point of view of the indirect reporter and the point of view of the reported speaker. Polyphony, as a language game, therefore does not consist in a mere 
summation of voices, but in the integration of them within a relationship of commentary between the voices (one voice being a comment on the other). Polyphony involves commentary in that the reporting speaker can present the reported speaker's voice in a derogatory way (he may shout, speak sardonically, express rage, etc. when expressing the reported speaker's voice). We may very well speak of a concert of voices, which are however, regimented by the reporting speaker and by the inferences of the hearer. The hearer is capable of using inferences to differentiate voices, but also to notice if some element is added illegitimately by the reporting speaker. So, the game is not only one which has the reporting and the reported speaker as its main participants, but one where the hearer is an important judge, who can add things not said or subtract unnecessary elements.

\section{Davidson on indirect reports}

In this paper, I am not after the logical form of indirect reports. I am mainly after a pragmatic treatment based on the notion of the language game. However, I will briefly mention Donald Davidson's (1968) treatment of the logical form of indirect reports because it is the treatment that best accords with my view of indirect reports as language games. According to Davidson a sentence such as:

\section{John said that Mary is in Paris}

is to be accounted for, truth-conditionally, by the following logical form:

John said that. Mary is in Paris.

In other words, Davidson asks us to consider a proposal according to which the complementizer 'that' disappears from logical form, being replaced by the pronominal 'that'. A propos of this, Davidson briefly mentions historical considerations on the development of the complementizer 'that' from the pronominal 'that'. Now, I am aware that there is a strand of research that builds on Davidson's proposal (sometimes aiming to ameliorate it, sometimes aiming to destroy it; see Rumfitt 1993). But as in this paper I am mainly interested in the language game 'indirect report' and in the pragmatics of indirect reporting, I will skip such discussions. I will nevertheless rehearse some considerations by Davidson, which are now very popular in philosophy:

We tried to bring the flavor of the analysis to which we have returned by rewording our favorite sentence as "Galileo uttered a sentence that meant in his mouth what "The earth moves" means now in mine". We should not think ill of this verbose version of "Galileo said that the earth moves" because of apparent reference to a meaning ("What the earth moves means"), this expression is not treated as a singular term in the theory. We are indeed asked to make sense of the judgment of synonymy between utterances, but not as foundations of a theory of Language, merely as an unanalyzed part of the content of the familiar idiom of indirect discourse. The idea that underlies our awkward paraphrase is that of same saying: when I say that Galileo said that the earth moves, I represent Galileo and myself as same sayers. (Davidson 1968, 140).

Now, by extrapolating this excerpt, I want to emphasize that for Davidson it was clear that oratio obliqua is a discourse involving multiple voices. The mouths 
uttering the words belong to different persons. The sentences actually uttered, as far as Davidson is aware, may very well be different provided that the two utterances are semantically equivalent, that is to say their imports are truth-conditionally equivalent. There are two voices, two points of view involved, and an indirect report is, obviously, a transformation of the original utterance. Baldwin (1982, 273) claims that one defect standardly attributed to Davidon's formulation of the theory is that it seems to imply that there is one more utterance besides the utterance 'The earth moves'. This, which from a philosophical point of view, counts as a defect (which could be remedied anyway, if we follow the discussion in Baldwin), is not necessarily a defect from a linguistic point of view as it makes us see that the case of indirect reports (and its logic) depends on the tension between the reported speaker's voice and the reporter's voice. It is no surprise that there may be two utterances, whose content is fundamentally the same, although parts of it, those parts which do not count for the provision of an extensional semantic theory of indirect reports, need not be the same.

The considerations by Davidson on p. 143 are not equally famous, but in my opinion they lead to a view of indirect reports as language games, in the study of which pragmatics is prevalently or at least substantially involved:

We would do better, in coping with this subject, to talk of inscriptions and utterances and speech acts, and avoid reference to sentences. For what an utterance of "Galileo said that" does is announce a further utterance. Like any utterance, this first may be serious or silly, assertive or playful, but if it is true, it must be followed by an utterance synonymous with some other. The second utterance, the introduced act, may also be true or false, done in the mode of assertion or play. But if it is as announced, it must serve at least the purpose of conveying the content of what someone said. (Davidson 1968, 143).

At this point we notice that Davidson has touched on a deep issue-the content of indirect reports may be determined pragmatically. So, it is possible that the utterance $x$ following "Galileo said that" may be synonymous with an utterance which is not truth-conditionally equivalent to $\mathrm{x}$, but can be made pragmatically equivalent to $\mathrm{x}$, say through pragmatic intrusion. (In other words, we should consider the explicatures as truth-conditionally equivalent). In general, the excerpt above raised the important question that the purpose and the speech act communicated by the indirect report may prominently figure when we try to establish whether the reporting utterance and the original utterance match in content. I discussed, however, briefly this notion in Capone (2010a). For the sake of this discussion, it is important to point out that Davidson thinks we must separate truthconditional content and pragmatic content. Even if Davidson does not move towards a radical pragmatic view of indirect reports, it is clear that the notion of pragmatic equivalence is what is at stake when we say that the original utterance and the reporting utterance match in content. Suppose, for example, that the original utterance is:

\section{Mario is really brave}

and the reporter, whether accurately or not, transforms (2) by uttering (3) (with a view that (3) and (2) match in content). 
3. John said that Mario is a lion.

Should we say that the indirect report matches in content the original utterance? For some purposes, we may be persuaded to answer positively, even if the locutionary forces of these utterances (clearly) do not match. It may be argued that (2) and (3) cannot be taken to convey the same content, as metaphorical meaning is in some sense non-conventional (as referee 2 says, in order to guarantee sameness of content the metaphor would have to be conventional. But then it would be well on its way to being a lexical sense of the expression). I am not persuaded by the idea that two utterances match in content only if the conventional meanings match, but of course I agree with referee 2 that a metaphorical expression conveys (usually) much more than the conventional expression it was used to replace. There are effects in terms of poetry, force, rhetoric which are not expressed by a nonmetaphorical expression. But granting some differences, think now of the following language game. We can report thoughts by using certain cards, on each of which a certain word is printed. We do not have cards for every word. So we must do what we can to express our thoughts, and our readers must accept the approximations which we can use. Now suppose we have a card for 'lion' but not one for 'brave'. Could we engage in the language game of reporting the speech act, nevertheless? The answer, in the context of this language game, with its obvious limitations, is positive. To report 'John said that Mario is a lion' is certainly better than nothing and our readers will have to put up with the limitations of our language game. However, even in a different context, a reporting speaker may want to modify somewhat the original utterance, to convey something which John did not say but probably wanted to say (or would have said in different circumstances). Perhaps the reporting speaker is judging that his indirect report is more faithful to the speaker's intentions than the original speaker's words. Perhaps the reporting speaker is relying on clues which are not available to the hearer (or reader) and is reconstructing the speaker's intentions to the best of his own abilities. After all, are we not allowed to infer and voice someone's intentions, even if that person was not capable of fully expressing them? Now, this argument, clearly, has taken me some way from the considerations by referee 2 .

In ending this section, I want to remind readers that the initial Davidsonian formulation of indirect discourse was criticized because it was immune to intentionality (Baldwin 1982, 272) and was thus later replaced by a better analysis which was completely extensional (Baldwin 1982, 273):

Galileo said $\mathrm{x}$ iff $(\exists \mathrm{y})$ [Galileo uttered y and Same in content $(\mathrm{x}, \mathrm{y})$ ].

\section{Capone (2010) and indirect reports}

In Capone (2010a) I advanced a number of ideas on how to capture constraints on replacements of co-referential NPs in the context of indirect reporting (and, in particular, in the complement that-clause). The explanation may be parallel, but not identical with the one I gave on the issue of belief reports in Capone (2008). Such an explanation rests on the idea that replacements of co-referential NPs should not alter the speech act which the indirect report aims to report (or describe) 
and that the original speaker would like to see herself reported in such a way that it does not attribute her offenses, impoliteness, rudeness, obscenity, and also slurring. In other words, reporting must be done in a way that the voice of the reporter is separated from the voice of the reported speaker or, if this separation is not possible, in such a way that the original speaker's voice is prevalent. Why should the reported speaker's and NOT the reporting speaker's voice be prevalent? I assume that it is a matter of relevance. Since we are dealing with the verb 'say', we are happy to primarily express the original speaker's voice and then the reporting speaker's voice, but only if this is possible. I now succinctly sum up the main points of Capone (2010a).

The practice of indirect reports rests on the following principles:

\section{Paraphrasis Principle ${ }^{6}$}

The that-clause embedded in the verb 'say' is a paraphrasis of what $\mathrm{Y}$ said that meets the following constraint: should $Y$ hear what X said he (Y) had said, he would not take issue with it, but would approve of it as a fair paraphrasis of his original utterance.

The following is a precisification of the previous Principle, which remedies some of its defects, as it does not only take content into account, but also makes reference to form.

\section{Paraphrasis/Form Principle}

The that-clause embedded in the verb 'say' is a paraphrasis of what Y said, and meets the following constraints: should $\mathrm{Y}$ hear what $\mathrm{X}$ said he $(\mathrm{Y})$ had said, he would not take issue with it, as to content, but would approve of it as a fair paraphrasis of his original utterance. Furthermore, he would not object to vocalizing the assertion made out of the words following the complementizer 'that' on account of its form/style.

In my paper I also discussed possible objections to the Paraphrasis/Form principle. Since this discussion will be amplified in the present paper, I present some of the original discussion in this section.

Depending on the context, I needn't be beholden to the original speaker's 'approval' of my paraphasis as fair, nor need I avoid manners of speech which the original speaker would shy away from. In such contexts, if John said of a person $\mathrm{x}$ that he will be coming to the party, my report to that effect is true whether I refer to person x politely, as John would approve of, or impolitely, as (let us imagine) my hearer would approve of. John may, upon hearing my report, demur: "Well, I don't know why you'd call x a jerk but, yes, I did say he was coming to the party". The Paraphrasis Principle and the author's other remarks are intended to rule out

\footnotetext{
6 This position is somewhat reminiscent of Seymour's (1994) treatment of indirect reports, in which reference to a translation of the reported sentence is explicitly incorporated in the semantics of indirect reports.
} 
contexts of indirect reporting that seem to allow this type of license with the original speaker's words.

As I said in Capone (2010a), I am quite open to the possibility that in suitable contexts ${ }^{7}$ one should be able to replace an NP with a coreferential expression in the that-clause of an indirect report. However, I stick to the proposal that, in the absence of abundant contextual clues and cues allowing us to separate the original speaker's voice from that of the reporter, the default interpretation of the utterance conforms to the paraphrasis rules stated above.

\section{Some considerations on Wieland on indirect reports}

Wieland (2013) considers that most theories on indirect reports conclude that the practice of indirect reporting must be studied essentially from a pragmatic point of view. Wieland, however, refuses to accept that one cannot say something systematic and of general import about the practice of indirect reporting. She is adamant in considering the case of indirect reporting distinct from the case of quotation and the case of belief reports. Now, if such propositions are accepted, it goes without saying that indirect reports allow a certain amount of substitution (of NPs having identical referents) and thus it is not to be taken for granted that they are characterized by opacity. Since they are not expressions of belief, the attitude of the original speaker need not interfere with substitution of NPs having identical reference. Now, I do not want to dispute these propositions, as there is obviously some truth in them. But it is possible that the inferential step from these propositions to the lack of opacity exhibited (according to Wieland) by indirect reports is not necessary or needed; in other words, it may distract us from some obvious connections between a theory of quotation and a theory of indirect reports. And the most obvious link between the two theories is that in both cases we need to establish which voices belong to the various segments making up the utterance. Indirect reporting (as made clear by Cappelen and Lepore 2005b) involves mixed quotation, at least in some cases. So the only way to make the two issues separate now is to insist on quotation as being characterized strictly by opacity and indirect reports as not being characterized by opacity (or in being characterized less strictly by it). However, if we grant that indirect reports can contain quoted segments, it is less clear that opacity and lack of opacity can be used to distinguish the two cases. In my article on quotation (Capone 2013) ${ }^{8}$ I insisted that inverted commas need not always be used to signal the quotative function, as they are often absent in the oral language. Rather we need pragmatic ways of signaling that certain segments are being quoted. But if this is the case, then it goes without saying that implicitly many segments of indirect reports can come out as being quoted, at least through

\footnotetext{
${ }^{7}$ One of the most typical contexts allowing substitutions of coextensive NPs is one where the NP used in the original speech act would not allow the hearer (of the indirect report) to identify the referent, and thus the reporter deems it necessary to use an NP which does indeed allow the hearer to recognize the referent (See also Capone 2008). On the role played by context in inferential processes see Capone (2010b).

${ }^{8}$ See also Saka (1998) for a discussion of quotation in philosophy of language.
} 
some pragmatic means. These differences of opinion between Wieland and myself do not prevent me from seeing the importance of her other considerations on indirect reports. And it is on these crucial considerations-which I should say are both important and controversial - that I want to concentrate now.

Somehow departing from my considerations in Capone (2010a), Wieland argues that in some contexts, when the reporting speaker has a purpose which serves to advance the communication process - rather than impeding it through the use of an NP whose semantic import is not known to the hearer-it is licit to intersubstitute co-referential terms. ${ }^{9}$ Consider this co-referential substitution:

4. A: My favourite tapa is patatas bravas.

B: A said that her favorite tapa is the third item on your menu.

Wieland says:

In this case, the term 'patatas bravas' is substituted with a definite description with a value that can only be determined in the reporting context. It would be implausible to suggest that the original speaker meant anything like 'the third item on your menu' in the original context of utterance. Nevertheless, ordinary reporting practices take advantage of this sort of inter-substitution (Wieland 2013).

And I agree that in reporting the original utterance by transforming an NP in this way allowing the hearer to get to the referent in a quicker way, a speaker has a practical purpose. This practical purpose does not completely transform the original utterance, in ways that might give rise to complaints by the original speaker. Furthermore, this is clearly a case in which the NP used to transform the original NP is quite neutral; and most importantly, by using it, a hearer can have access to the thought entertained by the original speaker (in saying whatever he said), as the NP which was used as a replacement will eventually, albeit not immediately now during the indirect report, but once the report has been heard in its entirety, allow the hearer to reconstruct the item that is momentarily missing. I propose to use a technical term for items such as 'the third item on the menu' - these are sort of pro-forms, but unlike pronominals, which point to objects, they are quotative proforms, as they point to locutionary segments of the talk. (Obviously they refer to types, rather than tokens).

There are other interesting transformations which Wieland draws our attention to. Consider the following, from her paper:

5. A: I went to the taco stand and bought a soda.

B: A said that she went to the taco stand.

B's utterance is clearly obtained by conjunction elimination. Now apparently, this is the case of an innocuous, even innocent transformation. However, there are doubts that this transformation can be effected without consequences when conjunction is involved in an explicature, as in the famous examples by Carston (2002). So, suppose that Churchill said (6)

9 This is in line with Wieland (2010). 
6. The Germans raided London and we fought them back

or

7. The Germans raided London but we fought them back.

There may be explicatures or conventional implicatures (see Potts 2005) attached to a certain conjunction (and as a consequence, we fought them back). Thus eliminating a conjunct from an indirect report in such cases, gives us the impression that part of the original meaning is lost. So if (7) is reported as (8)

8. Churchill said that we fought the Germans back

We have partially reported the utterance. It is a partial report. Could a partial report be felicitous? There are contexts in which it might and contexts in which it might not be felicitous. So, it is not straightforward that conjunction elimination is an operation that can be used always felicitously in indirect reporting. ${ }^{10}$

Consider now modifier elimination. It might be thought that modifier elimination is an innocuous logical operation in indirect reports, simply because it is supported by logical/semantical entailments:

If NP [VP ADVB V NP], then it must be the case that NP [VP V NP].

So, if I met a beautiful woman at the party, it must be the case that I met a woman at the party. And if John says:

9. I met a beautiful woman at the party

it could be claimed that one could report felicitously:

(9) John said that he met a woman at the party.

But now suppose that on a different occasion John said of the same woman, unaware that she was that woman:

10. That woman is horrible.

Now we could conjoin (9) with (10), since after all John was talking about the same woman and obtain:

11. John said he met a woman, who was horrible, at the party.

\footnotetext{
10 A case for the potential infelicity of partial indirect reports. Mrs Savatta was the headmistress in a high school in Italy. At a meeting with the teachers, she said 'Suppose I say that Mr Buccheri is an idiot." Of course, she said that in a context, and her context was provided in part by her previous utterances. There was a rhetorical relationship between this utterance and the previous ones-she was presumably using this utterance as part of a (complex) argument. However, the teacher was offended by this and a long legal quarrel followed. The secretary of the meeting reported just this utterance but completely omitted the previous utterances, thus making it appear as if the headmistress was completely mad. Granting that there was something amiss in this linguistic contribution, however, there was something completely amiss in the report of her utterance, because it was a partial report. Cutting an utterance and reporting just part of it can make things appear in the wrong light, as the function of an utterance in a sequence of speech (in particular the rhetorical connections) seems to have been lost and the immediate result is that the speaker can be presented as a deranged person.
} 
So the problem I see in modifier elimination is that it will allow us to conjoin a report of what John said on some occasion with a report of what he said on another occasion which contradicted what he said before. ${ }^{11}$ The contradiction passes unnoticed, if we simply support the view that modifier elimination is a feasible operation in indirect reporting.

I should notice that Wieland adds a little later that "Some modifier eliminations and modifier introductions alter the original utterance in a pragmatically infelicitous way and some do not. These are governed by pragmatic constraints on relevance and not semantic rules." I quite agree with these considerations, even if I would take side with a more general position in which partial indirect reports are always less informative than exhaustive indirect reports and thus they require a context that justifies the extra cognitive effort required in the logical operation of the reporting (since reducing involves an extra logical operation). This may well be in line with the general position by Sperber and Wilson (1986) according to which Relevance is a balance of positive rewards (effects) and cognitive efforts.

Another important consideration by Wieland is that the logical operation inference can be incorporated into indirect reports. She felicitously calls this case: inferential indirect report. An example of this practice might be the following (always from Wieland 2013):

\section{A: I didn't fail any students.}

\section{B: Professor A said Maryanne passed her exam.}

Wieland says: "Just as long as B knows that Maryanne is one of A's students, then B can felicitously report A's utterance in this way. The fact that the intersubstitutability of co-referential terms and paraphrase on the basis of inference are not only possible but commonplace suggests that an indirect report does not function to replicate the original utterance, and it does not even function to convey content that is identical to the original utterance, but rather its pragmatic function is to convey whatever is relevant about the original utterance to the reporter and audience given new facts about the reporting context". Now there is something weird about this case. Suppose Professor B is universally known as passing only very good students (he fails those who are passable for other professors). Then, given what is known about Professor B's beliefs, it could be claimed that Professor B said that Maryanne was a very good student. Then suppose it is well known that professor B believes that all his good students will become University Professors. Then it will be held that Professor B said that Maryanne will become a University Professor. But it is not clear that Professor B said all these things. Now, while in

11 The problem is more or less of the same type as noted by Igor Douven in connection with the pragmatics of belief. One should not make inferences that are likely to deceive one's future self. Now, while clearly the inferences Douven has in mind are pragmatic, here we have a logical operation of modifier elimination. But the result is similar as one's future self may be misled by being allowed to make other logical operations (such as conjunction). By the way, I am not thinking that modifier elimination and conjunction are related things. However, there is a danger in using both operations, sometimes. 
my own examples, the problem might derive from identifying the words said with the beliefs normally associated with those words, in Wieland's case the problem is even worse, because professor B is said to have said something without even believing it, as he never had any beliefs about Maryanne (suppose the examination was carried out on papers marked by a code, to make them anonymous). There might be interminable discussions on points such as these-and it is good that these discussions should be undertaken. My intuition is that we are at a point in which it is not easy to distinguish between legitimate cases of indirect reports and cases that are parasitic on them. It is possible that this might be a loose usage. But even if a loose usage, it is still an indirect report, and thus Wieland does well to point out that inference may play an element in reporting. (Given that it may play a role in establishing the truth of a report, I propose that we give great consideration to Wieland's case).

The case just discussed reminds me of cases in which pragmatic inferential augmentations are banned by Igor Douven's (2010) the Pragmatics of belief and, in particular, by his Epistemic Hygienics.

Igor Douven proposes that when we store a belief (in the form of an assertion or a sentence or a thought), we avoid storing it together with inferential augmentations which may lead us later to remember something which was not the case. This is called Epistemic Hygienics. A vivid example which comes from that paper is the reference to Gettier's problem. Suppose I know that $p$. Then, even if I can infer ' $p$ or q' from 'p', it will not do to store in memory ' $p$ or q' if that is going to create trouble later, leading me to believe something that is false or unjustified. We may remember that what creates havoc in Gettier's problem is the shift from ' $p$ ' to ' $p$ or $q$ '. Keeping in memory ' $p$ or q' when one believes 'p' may possibly create trouble, as that may lead to an apparently justified belief which happens to be true.

The Principle which will avoid us many problems in the future is the following: Epistemic Hygienics (EH): Do not accept sentences that could mislead your future selves. ${ }^{12}$

Other interesting examples by Douven are the following:

\footnotetext{
12 A referee makes an important consideration and says that virtually it could be possible for any sentence to mislead one's future self (so we need a story about what it is that makes a sentence a candidate to mislead). Well, consider the sentence: 'John went to the cinema'. I may utter it having in mind the referent 'The Apollo', but if I memorize the sentence without associating the referent 'The Apollo' to the NP 'the cinema', I may end up in the future using the sentence to refer to 'The Odeon'. After all could not mistakes of this sort happen? To avoid the overgeneration of entailments, we would probably have to keep in mind that we need to memorize not only abstract sentences, but sentences uttered in context, hence complete thoughts. Pragmatic intrusion is a good way to avoid the over-generation of possible entailments. Having done so, we still have to avoid those entailments which are likely to mislead our future selves. Of course, I should note that for Douven the problem is not an entailment 'per se', but the fact that when we commit things to memory, we could keep the entailments separate from the sentences that generated them and we could even end up, in extreme cases, admittedly, forgetting the sentences which generated those entailments, while retaining the entailments in question. And this is quite bad, because we will end up remembering things which are likely to mislead us and have negative consequences on action.
} 


\section{Peggy's car is blue;}

14. Peggy's car is bluish.

Now, it is clear that if Peggy's car is blue, it is also bluish (blue being a stronger gradation of bluish). However, if one commits to memory 'Peggy's car is bluish' when one believes that it is blue, one will commit to memory a piece of information which may possibly mislead one's future self (Suppose that, in a couple of days, the same person is asked by Mary to say the color of Peggy's car; he says that it is bluish; then Mary is not able to identify Peggy's car in the office's garage. Some trouble has ensued). Douven compares memorizing or committing to memory to writing notes (e.g. Turn off the gas) which will be of use to our future selves. If memories are like notes, we should avoid writing notes that mislead our future selves.

Igor Douven's paper is of great importance to epistemology but also to pragmatics. He shows that pragmatics and epistemology are intimately connected. While Igor Douven's story can be interpreted in the light of more general principles of cognition (a memory that is misleading obviously is a case in which a believed assumption is more costly than beneficial in terms of cognitive effects; positive cognitive effects being those which put me in touch with reality, not those which drive me away from it), I cannot do this in this paper.

Now, to return to Wieland's case. How can we deal with it in terms of the pragmatics of belief by Igor Douven? If we accept:

Epistemic Hygienics (EH): Do not accept sentences that could mislead your future selves,

it is clear that creating indirect reports by resorting to inferential steps that can mislead our future selves is illicit.

So, if on the basis of (12a), I make the indirect report (in (12b), I will be entitled in the future to expect that, on meeting Maryanne, Professor A will recognize her and say 'Hello' to her. ${ }^{13}$ But this may never happen, if he passed her only by marking an anonymous paper. Nor should we expect that, being really impressed by her paper, on seeing a paper by Maryanne in the Journal of Philosophy, he will be able to connect this paper to his past positive experience (commenting "Oh, this

\footnotetext{
13 A referee said that $12 \mathrm{~b}$ does not entitle anyone to expect recognition. And, of course I agree that Professor A is not expected to recognize Marianne. But, given $12 \mathrm{~b}$, is not a hearer led to believe somehow that Professor A has someone in mind (possibly just the name and the thought that a person with that name has passed the exam)? However, minimal, this thought seems to have been conveyed. Of course, one could adjust the context somehow. Suppose everyone knows that Professor A does not look at the names on the papers, he just covers them (or asks his secretary to do that) with colored sellotape. Then he marks the papers and gives them to his secretary who assigns marks to individual students. This habit is so remarkable that professor A has become famous for this. Then, in this (heavily contrived) context, the utterance 'Professor A said that Marianne passed the exam' could be interpreted as 'Professor A passed Marianne's paper'. But, even with all this contextual adjustment, we have a feeling that 'Professor A passed Marianne's paper' and 'Professor A said that Marianne passed her exam' are very different utterances, as the latter implies somehow that Professor A said something of Marianne, that he had her or her name in mind, at some point.
} 
is another paper by Maryanne). But all this makes sense, if we are aware that there is something strange in the practice allowing us to go from the first step of (12) to its second step.

The last case discussed by Wieland that is of considerable interest (presumably based on some cases I myself pointed out in Capone (2010a), as kindly noted by Wieland) is whether we should consider the literal or the metaphorical/indirect/ ironic level as the basic level of content of an indirect report. Wieland seems to opt for the view that the content of an indirect report should be constituted by interpreted and not by literal segments of speech. Thus an utterance of (15)

\section{Mary is a lioness}

should be reported as:

16. John said that Mary is brave.

However, I notice that it is not cases of metaphors that are particularly thorny, because here by reporting the literal level of meaning, one allows the hearer nevertheless to compute the indirect or not literal level of meaning. The most problematic cases are those of irony, because the context of the original utterance is missing (or may be missing) and thus the hearer cannot move from the literal to the ironic (or echoic) meaning. Thus the transition from (17) to (18) is not easy:

17. The talk was very good.

18. He said that the talk was really bad and he didn't like it much.

It appears that Wieland is uncontroversially moving towards a view of indirect reports in which the content of the indirect report is only the intended meaning, rather than the (possibly unintended) literal meaning ${ }^{14}$ of the original utterance. Now, if such a view is accepted, indirect reports could NOT be used as Cappelen and Lepore (2005a) do as tests for literal meaning or minimal semantics. My impression is that in context we must settle whether an indirect report is a literal or a non-literal report. There is evidence in favor of both views. Given the fact that it is possible to use direct quotation, when we want to mention the words used, the use of an indirect report for the same purpose would ultimately obtain the same effects of a quotation, but with great processing efforts (as one will ultimately compare the quotative construction with the indirect report). However, given that indirect reports are often mixed with quotative segments and given that quotation is (as I claimed in Capone 2013) a radically pragmatic operation, it is possible in theory that an indirect report might overlap with a quotative structure (see also Burton-Roberts 2006) - which is what happens in the most thorny examples by Cappelen and Lepore. I will stop the discussion here, as I do not want it to slide into a discussion of Semantic Minimalism. In this paper, I am mainly interested in

\footnotetext{
14 Of course, a literal meaning can be intended, in which case I think Wieland would have to accept that it is the content of an indirect report. If the literal meaning is not intended, in the sense that it is superseded by non-literal elements which are speaker-meant, then Wieland will not accept it as part of the content of the indirect report.
} 
the polyphonic structure of indirect reports and it is this aim I have in mind throughout. The overlap between quotation and indirect reports amply attests to this polyphonic structure.

A case not discussed by Wieland, which certainly fits the typology of examples she proposes, is that of how to report an ungrammatical utterance. Surely we should ask ourselves whether correcting an ungrammatical original statement by proposing an indirect report from which the error has been removed (abiding by the Principle of Charity) results in altering drastically what the original speaker said and in such a way that s/he would not approve of the indirect report. And can indirect reporting with correction result in opacity, in that the indirect report purges the original speaker's thought of something that was essential to the thought? In other words, we want to establish whether opacity only rests on the impossibility of intersubstituting co-referential NPs or whether it also rests on the impossibility of intersubstituting coreferential sentences one of which is syntactically incorrect. Paradoxically, the case is not of importance for the illiterate speaker, who attaches little importance to grammar and who may even be unaware of the substitution. However, consider what happens when the original speaker is a grammarian and the original utterance is reported through an indirect report whose grammar exhibits an element with which the original speaker may take issue. Fidelity to the grammar of the original statement may well depend on the context. If we are in a context in which we have to assign marks depending on the grammatical correctness of what the original speaker said (suppose we are marking students' papers), even slightly improving the grammar of her original sentence in an indirect report may be considered unacceptable. In this case mixed quotation may be deemed necessary.

\section{Indirect reports and quotation}

While scholars are generally adamant that there is a clear-cut distinction between quotation and indirect reports, this paper is, in fact, blurring these two practices. And the result of blurring the two practices fits in with the idea that opacity is a phenomenon to be found both in quotations and in indirect reports. In fact, the Davidsonian treatment of indirect reports also involved the blurring of quotation and indirect reports, as the complementizer 'that' for Davidson was a demonstrative pronominal and the thing which followed the demonstrative pronominal could be easily assimilated to a quotation (which explained where the opacity came from) (See Baldwin's 1982 important considerations, which agree with this ${ }^{15}$ ). Current scholars try to keep apart indirect reports and quotation-and perhaps their practice is correct up to a point. However, doing so in a rigid manner

\footnotetext{
15 Baldwin $(1982,273)$ writes: "Davidson argues against such quotational theories and thereby implies that his paratactic theory is not a quotational one. But he treats quotation as abbreviated spelling out, and if, more sensibly, one treats quotation marks as a demonstrative device, and one treats the symbols within the quotation marks as a display of that which is referred to by the demonstrative, then the difference between paratactic and quotational theories becomes one largely of notation."
} 
would prevent us from understanding where opacity comes from in such cases. Even if we grant that indirect reports are not always opaque, we surely must concede that they are preponderantly opaque. And even if they were only sometimes opaque, we would still have the trouble of explaining where the opacity comes from. And of course, the opacity of indirect reports comes from the fact that quotation and indirect reports are similar to some extent, as invariably proven by the practice of mixed quotation (in indirect reports). I want to believe that mixed quotation is not just a quirk, something that occurs sometimes, but is something that occurs frequently, since I have accepted (Capone 2013) that quotation both in the oral and in the written language can dispense with quotation marks and can resort to pragmatic marking. Given that any segment of an indirect discourse could be marked pragmatically as being mixed quoted, it is clear that the analogies between quotation and indirect reports are quite striking.

Suppose that we accept what I said in Capone (2009) on cancellability of explicatures (namely that explicatures are NOT cancellable). Then if we have pragmatic clues leading us to interpret a linguistic item as enveloped in inverted commas, the quotational interpretation cannot be cancelled, but will amount to a pragmatic intrusion into truth-conditional meaning. From this it follows that it will not do to replace that linguistic item with another coextensive item, because, otherwise, the speaker's commitment to having uttered that thought will evaporate. But this is exactly what opacity amounts to. We cannot replace a linguistic item with a coextensive one, without expressing a different thought. However, we have obtained opacity through some pragmatic means. It is not exactly semantic opacity we are writing about (to be more precise).

But now I want to pursue this line of reasoning further. Consider taboo words, usually relating to sexual organs, etc. Scholars have insisted that, despite the fact that a speaker takes great pains to distance herself from the use of a taboo word, thanks to quotation, she cannot really manage to do so, and for some strange reason, still to be explained adequately, the taboo word is assigned to her voice as well. So, consider the following example:

19. Mary said that '....T.....'.

(Where $\mathrm{T}$ stands for a taboo word inserted within a sentential frame .....). Regardless of the framing device of quotation, the responsibility for the taboo word is assigned equally to Mary and the (direct) reporter. Now, we would expect the matter to be different in indirect reports. Given that 'that' is not a demonstrative pronominal (as the Davidsonian analysis has it), but only a complementizer, the that-clause should come from the perspective of the indirect reporter. Thus we could expect, if there was a real difference between direct quotation and indirect reports, that only the reporter would be responsible for the taboo word in the following utterance type: 


\section{Mary said that ..... T....}

But this expectation is not born out. We equally attribute the $\mathrm{T}$ word to the reporter and to the original speaker. ${ }^{16}$ And we possibly attribute the gaffe to the original speaker to the same extent as to the reporter. ${ }^{17}$ So things stand exactly in the same way, as far as obscenities and other taboo words are concerned. Now, given that we are willing to give similar analyses of the indirect reports and of the direct reports in these cases, it is clear that neither quotation marks nor the complementizer can prevent responsibility from being assigned to the reporter. The two different functions of the complementizer and of quotation marks would lead us to expect that quotation marks could be more protective for the reporter, but this is not the case. The presence of the complementizer in indirect reports would lead us to expect that the complementizer could be more protective for the original speaker, but this is not the case. And why not? The truth is that if quotation and concealed mixed quotation in indirect reports are triggered and interpreted pragmatically, then we have a pragmatic machinery capable of explaining why the responsibility of a certain segment of talk is assigned to the original speaker, or both to the original speaker and the reporter.

Now, at this point, we can go on using the machinery of indirect reports for direct quotations as well.

\section{Paraphrasis Principle}

The that-clause embedded in the verb 'say' is a paraphrasis of what Y said that meets the following constraint: should $\mathrm{Y}$ hear what $\mathrm{X}$ said he (Y) had said, he

\footnotetext{
16 The reason for this is that the reporter could have chosen a different word (a more descriptive strategy), but he did not do so (thus he is guilty and responsible for the words reported). The original speaker is attributed the words by default, because the statement is about what he said, and the partial responsibility of the reporter cannot eradicate the topicality of the indirect report, as that is ABOUT the utterance proffered by the original speaker. If the original speaker did not utter those words, why should we report them, allowing the hearer to possibly attribute the words to the original speaker? A report that focuses on slurring or taboo words in case the original speaker did not use those words is infelicitous and irrelevant, since, do not forget, the purpose of an indirect report is to focus on what the original speaker said, NOT on what he did not say.

17 Referee 2 says that we can easily imagine a reporter indirectly reporting an original utterance that contains a taboo word using a euphemism instead or pointing out heavily that the taboo word attaches explicitly to the original speaker in some way. The tendency of reporters to use descriptive euphemisms for taboo words, e.g. 'The S-word' for 'Shit' or the 'F-word' for 'fuck' suggests we attribute the taboo word to reporters more than to the original speaker. I think these considerations are illuminating. I certainly agree that in reporting a speaker is sensitive to certain rules (a prohibition against using or even mentioning taboo words). But the fact that the reporter is dissociating himself from the use of those words clearly is an indication that in the world shared by the reporter and the reported speaker using those words is prohibited. And if merely mentioning those words is prohibited, we can easily imagine that there is an even stronger prohibition against USING those words (and presumably those words were used and not only mentioned by the original speaker). So I agree with the referee only up to a point, as I take the fact that the reporter is distancing himself from the T-words to reveal a judgment against the use of those words (in the original utterance) in the first place.
} 
would not take issue with it, but would approve of it as a fair paraphrasis of her original utterance.

\section{Paraphrasis/Form Principle}

The that-clause embedded in the verb 'say' is a paraphrasis of what Y said, and meets the following constraints: should $\mathrm{Y}$ hear what $\mathrm{X}$ said he $(\mathrm{Y})$ had said, he would not take issue with it, as to content, but would approve of it as a fair paraphrasis of his original utterance. Furthermore, he would not object to vocalizing the assertion made out of the words following the complementizer 'that' on account of its form/style.

According to these two principles, we can explain why the responsibility for the obscenity is assigned to the original speaker both in the case of indirect reports and in the case of direct quotation. Of course the case of indirect reports flows easily and directly from the principles above. In the case of quotation, we need a D-tour. It is pragmatics that assigns the obscenity to the original speaker, by marking a segment as being quoted, since the point of the quotation is to assign her those words. It follows that if the pragmatics of quotation is ok, the original speaker would approve of the utterance that is being attributed to her.

Now, why is it that the reporter (both the direct and the indirect reporter) is guilty of obscenity? Why is it that the quotation marks do not protect her? And the answer is obvious. The reporter could have avoided reporting the locution and could have found ways of expressing the content in such a way that the content as well the obscenity could be perceived, without depicting the obscenity but by describing it. ${ }^{18}$ In this way, she would have dissociated herself (her voice) from the voicing of the obscenity. Now, in the indirect report, the original speaker is guilty of the obscenity to a greater extent because a segment of the indirect report is being mixed-quoted through the pragmatic machinery. Nevertheless, the reporter is responsible for the obscenity-even if to a smaller extent-because she could have reported the content by describing the obscenity rather than by depicting it. Since she preferred depicting to describing, he must be deemed guilty of not sparing the hearer the embarrassment of hearing the obscenity.

\subsection{Michel Seymour (1994) on indirect discourse and quotation}

My approach to indirect reports is reminiscent of the ideas expressed by Seymour (1994), which is a unique and, in my view, important paper on the close connections between indirect reports and quotation. Seymour is ambivalent between quotation proper and a domesticated view of quotation in which the quoted sentence describes an act of saying in the direct sense, but translates it according to the conceptual scheme of the reporter's translational manual. Now, if I am correct, Seymour allows a mixture of elements which reflect the quoted person's voice and elements which reflect the reporter's conceptual translation manual. So, if the (English) reporter reports 'She said that Mary went to Rome', it

18 See also referee 2's considerations, voiced in footnote 16. 
is possible that the original speaker used 'Maria' and 'Roma' in her utterance, but these are translated as 'Mary' and 'Rome'. The basic structure and content of the quoted item is the same, but certain interpolations were made. Now I believe that the great merit of Seymour's analysis lies in making us see that indirect reports are (normally) a blend of quotation and pure indirect reports. Pure indirect reports only represent a schematic summary made by the reporter of what the reported speaker said. The blended report couples this summary with a quotation structure, or couples a quotation structure with a use of the same sentence as if it was not quoted. In my view pure indirect reports do not exist or represent an abstract ideal, while the quotative approach to indirect reports (the approach according to which there are implicit quotation marks provided pragmatically inside the that-clause) is what I accept fully, provided that we accept that speakers and hearers rely on a pragmatic machinery allowing them to distinguish voices in the indirect report. So, does Seymour definitely abandon the Davidsonian analysis? Clearly he does not, since he blends a sentential approach (one that considers the sentence reported as if in quotation marks) with a paraphrase approach (in which content (regardless of the words used) is of paramount importance), and, furthermore, he accepts that indirect reports rest on a semantic theory based on the concept of truth, of systematicity and recursiveness. The fact that Seymour's (as well as my view) is a blend of the praraphase and sentential theories does not prevent the theory from being based on truth, since both paraphrase and quotation are structures which can be evaluated truth-conditionally. The theory is clearly systematic-being based on an abstract linguistic system that works through compositionality. And it is recursive, since it is possible to apply the same semantic rules recursively (John said that Mary said that Robert said that...).

My views, however, diverge from Michel Seymour in at least an important respect. My analysis of 'quotation' does not involve/presuppose (like his) a view based on names and is clearly based on a more developed view of quotation, say the one based on Recanati (2010) and the one I developed in Capone (2013), which is radical in claiming that pragmatics only is involved in deciding what the thing quoted is (a lexeme, a phonetic form, a written form, something somebody said, etc.). The other important difference is that I do not attach special importance to the ambiguity (whether semantic or interpretative, but I assume it makes sense to claim it is interpretative) between a sense of ' $\mathrm{X}$ said that' that is that of indirect reporting the content of what another person said and another sense which amounts to a special interpretation of quotation: in reporting ' $\mathrm{X}$ said that $\mathrm{p}$ ', one is basically saying that there is a proposition $p$, such that $X$ said ' $p$ ' and the content of ' $p$ ' is given (translated) by the sentence uttered by $\mathrm{X}$.

\section{Igor Douven's point of view.}

Reacting to my paper, Igor Douven (personal communication) writes the following:

I was wondering whether the paraphrase principles do not give too much weight to the speaker's approval. Couldn't a speaker have ulterior motives for disapproving some 
paraphrase, even if an impartial third party would approve of it? Perhaps the speaker regrets what he or she said. Or the speaker has a false memory about what he/she said and is perfectly honest (though mistaken, as seen from an impartial standpoint) in disagreeing with the paraphrase.

I was also wondering whether it would be worth trying to adopt instead of the paraphrase principles a principle like the following, which would connect to the current debate about contextualism in epistemology: ' $S$ said that $p$ ' is true iff by an assertion of that sentence the hearer comes to know what $\mathrm{S}$ said. As various epistemologists have argued, the standards for knowledge may vary with context. In some contexts, not much evidence is needed to gain knowledge; in other contexts, a lot of evidence is needed; and of course there are all sorts of intermediate cases. This might explain why in some contexts we think a loose paraphrase of what someone said is OK, while in others we feel that the speaker should stay very close to the original speaker's wording.

Ok. Consider the case in which disapproval comes because the speaker regrets having said what she said. We are not worried about this case, because if the speaker is honest enough, he must accept that his prior self would have approved (regardless of the reservations by his current self) the sentence reported in the indirect report, if it reflected the form and the thought he expressed in the original utterance.

The fact that a speaker disapproves what he said because she has a false memory of what she said does not worry us either-as we may confine ourselves to the case in which the original speaker remembers well what she said.

Considering the second part of Douven's comments, I am sympathetic towards a contextualist view of the matter. Presumably Douven connects ' $X$ said p' with knowledge of what $\mathrm{X}$ said on the part of the hearer. Transforming the issue of indirect reports into an epistemic issue amounts to bringing in contextualism. According to Contextualists (e.g. Keith De Rose 2009) the truth of a knowledge claim may depend on the amount of evidence required to assess it. In some contexts, we need a greater amount of evidence for the truth of ' $\mathrm{X}$ knows that $\mathrm{p}$ '. In other contexts, we need an inferior amount of evidence. In high stake contexts, the evidence needed is superior than the one needed in low stakes contexts. Analogously, in high stake contexts, we could say that the Paraphrase Principle is adhered to more strictly than in low stakes contexts. But this is not the only case in which we need to depart somehow from the Paraphrase principle. I have already discussed the case in which a speaker may be interested in letting the hearer identify a referent and thus may use a mode of presentation of the reference distinct from the one used or approvable by the original speaker. This situation is not linked to contextualism in a theory of knowledge, as the mode of presentation is different regardless of whether we are in a high stake or a low stake situation. Presumably, however, Igor Douven would want to say that we are in a low stake situations and this explains why the reporter is inclined to modify the mode of presentation used by the original speaker.

Now there are cogent reasons to be sympathetic to Igor Douven's treatment, even if a modification of his way of putting things is required. I propose to modify his assertion: 
' $\mathrm{S}$ said that p' is true iff by an assertion of that sentence the hearer comes to know what $\mathrm{S}$ said.

I prefer, instead:

an assertion of ' $\mathrm{S}$ said that $\mathrm{p}$ ' is felicitous iff by an assertion of that sentence the hearer comes to know what $\mathrm{S}$ said.

Should the Paraphrase principle be abandoned then? Perhaps a reformulation is needed that links it to high stakes contexts. Alternatively, one could opt for the position that assertions of ' $\mathrm{X}$ said that $\mathrm{p}$ ' which depart from the Paraphrase Principle are parasitic or loose uses. This would give greater legitimacy to the Paraphrase Principle while admitting that in some contexts we may depart from it somehow.

\section{Slurring}

If the considerations above on taboo words relating to the sexual sphere are correct, we would expect an analogy to work between taboo words in general and slurring. Slurring - to take up ideas by Lepore and Anderson (2013) amounts to using words that are derogatory and offend vast categories of people (usually minorities) such as Jews, Chinese (in USA), black people, homosexuals, etc. Our problem is not slurring per se, but what effects does slurring have on quotation and on indirect reports. Lepore and Anderson mainly deal with indirect reports-which use plugs such as the verb 'say'-but it is clear that indirect reports and quotations work in a parallel way when slurring is embedded in the quotation or indirect report structure. Lepore and Anderson reject the view that slurring persists in indirect reports (in that the reporter is being assigned responsibility for the slurring, rather than the original speaker) because of a conventional implicature (Williamson 2007) or because of a presupposition (see Williamson 2007 for discussion). Presuppositions usually do not escape verbs of saying, which are called 'plugs' because they tend to block presuppositions (see also Levinson 1983). But then slurs behave unlike presuppositions because they can survive embedding in plugs (even if they often survive embedding in negation, if-clauses, etc. like most presuppositions). Of course Lepore and Anderson do not consider a pragmatic view of presupposition (along the lines of Simons 2013), according to which, at least in several cases, presuppositions are projected through conversational implicatures (but then, in this case they are not presuppositions but conversational implicatures). We know how Lepore and Anderson would reply to a possible objection by Simons. If the persistence of the slurring is due to a conversational implicature, first of all we should account for the implicature through a pragmatic story. Second, the implicature would have to be cancellable, at least in some contexts. And yet we see that the implicature can hardly be cancelled, although it may be mitigated to some extent say in scientific contexts in which the writer makes it absolutely clear that her purpose in dealing with the prohibited word is scientific. If only mitigation is obtained through contextual variation, then it is hardly the case of a conversational implicature. The case against conventional implicature is more thorny. As usual, we are interested in cases of plugs, such as: 
21. John said that Mary is obstinate but brave (however, I do not personally see any contrast between being obstinate and being brave).

Plugs do not make the conventional implicature disappear completely, as the speaker of (21) presumably accepts that for someone it must be true that there is a contrast between being obstinate and being brave. However, they demote it from the epistemic commitments of the speaker. Thus, Lepore and Anderson are justified in holding that slurring cannot be a matter of conventional implicature.

One of the properties that characterises slurring is its persistence despite selfcorrection. This shows that the entailments of the slurring word cannot be un-said; and in this respect the slurring words are different from other words, which allow self-corrections. I could say 'Mary is tall. Oh, sorry, I meant short, I got confused'. These corrections are put up with in the oral language (less in written texts). But with slurring words, this is not the case, and no replacement or correction can repair the slurring which was caused by using a slurring word. Consider, in fact, the following:

22. Look at what that negro is doing-oh, I mean that black gentleman.

A repair like the one in (22) seems to make things worse, because it tends to add an ironic interpretation. ${ }^{19}$

Lepore and Anderson discuss at length the word 'Negro'-but they do not discuss-not even en passant - that in the past the word 'Negro' seemed to be acceptable or usable in American English. Consider for instance the 'I have a dream' speech by M. L. King. I was myself perplexed by such uses. Would they count as uses involving camaraderie among blacks or are they echoic uses to be wrapped in inverted commas? (It is possible to oscillate between the two views). It is difficult to answer this question in the context of this paper, as it involves diachronic considerations too. However, if there is at least one such context in which the slurring word, wrapped up by quotation marks, does not count as slurring, one could opt for a conversational implicature. So, the only cards on the table are the following: a conversational implicature and a rule of use. The rule of use view has been advocated by Lepore and Anderson. They claim that there is a prohibition against using slurring words. Of course, this prohibition works for the groups outside the potentially slurred groups. So, there is no prohibition for members of the slurred groups against using a slurring word. This could explain well why the contextual variation has such powerful transformative effects on the slurring potential of the work 'negro' or 'queer'. The conversational implicature view would no longer be needed-or could count as an alternative view having more or less the same explanatory power. But what would the conversational implicature view amount to? Without going into details, it would have to say that

19 Kennedy $(2002,19)$ writes about the word 'negro': 'nigger' is an ugly, evil, irredeemable word. He cites someone considering the word "the nuclear bomb of racial epithets" (p. 61). 
certain words are slurs in ordinary contexts where the speaker speaks for herself (and no direct report or quotative structure is involved), and they are slurs presumably because there is a societal rule against the use of these words. Then it would have to explain, on the basis of this general prohibition, why inverted commas or indirect reports do not rescind the responsibility of the indirect reporter from that of the original speaker who presumably is responsible for slurring. But now the conversational implicature view is parasitic on the rule of use advocated by Lepore and Anderson. So, it would be simpler to hold that the rule of use based on a societal Prohibition works both for the original speaker and the reporter. But if it was a rule of use, how can we explain the fact that quotation marks do not rescind the responsibility of the reporter from that of the original speaker? After all, it is commonly held that quotation involves mentioning (at least in semantic textbooks such as Lyons 1977). If it involves mentioning, why should a rule of use be applicable to the reporter? Clearly indirect reports do not pose a serious threat to Lepore and Anderson because it might be claimed by theorists that the complemetizer 'that' need not work like a demonstrative pronominal and the indirect reporter can be considered as one who uses the words in the that-clause, at least partially. What I have said before about the parallel considerations on quotation and indirect reports discourage us from this Pyrrhic victory, so cheaply obtained. I claimed that in indirect reports too the hearer is faced with the thorny task of separating the original speaker's from the reporter's voice. Thus, it is not impossible, especially in the presence of appropriate clues, to consider the slurring words of the indirect report as being embedded in inverted commas (in this case the original speaker would have to accept responsibility for the slurring). So the problem raised by quotation is not trivial. The rule of use advocated by Lepore and Anderson does not seem to work well, first of all because quotation structures as well as indirect reports intended as having a quotative structure do not allow us to pass the theory based on a rule of use (a prohibition), as the original speaker could be assigned major responsibility for uttering the slurring words. Second, we need to note that contrary to Lepore and Anderson, who claim that indirect reports containing slurring words assign greater responsibility for the slurring to the reporter than to the original speaker, ${ }^{20} \mathrm{I}$ claim that, if anything, a pragmatic theory like the one voiced in Capone (2010a) makes it the case that the original speaker has responsibility too. So, we need a pragmatic machinery like the one expressed in:

\footnotetext{
${ }^{20}$ Lepore and Anderson (2013) write that "Indirect reports and other attitudinal inscriptions fail to attribute slurring to whomever they report since the offense of the reporter "screens off", so to speak, the offense of whoever is being reported. This position is interesting, but needless to say, it would need greater justification.
} 


\section{Paraphrasis Principle ${ }^{21}$}

The that-clause embedded in the verb 'say' is a paraphrasis of what Y said that meets the following constraint: should $\mathrm{Y}$ hear what $\mathrm{X}$ said he (Y) had said, he would not take issue with it, but would approve of it as a fair paraphrasis of her original utterance.

\section{Paraphrasis/Form Principle}

The that-clause embedded in the verb 'say' is a paraphrasis of what Y said, and meets the following constraints: should $\mathrm{Y}$ hear what $\mathrm{X}$ said he (Y) had said, he would not take issue with it, as to content, but would approve of it as a fair paraphrasis of his original utterance. Furthermore, he would not object to vocalizing the assertion made out of the words following the complementizer 'that' on account of its form/style.

Now, these principles would allow us to assign the original speaker the principal responsibility for the slurring, taking for granted or presupposing Lepore and Anderson's rule of use (or prohibition). The reporting speaker, given such a use, is guilty of not having used an alternative word $^{22}$ or a description, rather than a segment which has depictive properties. Given that she has not avoided the slurring word, when she obviously could do so, she herself becomes responsible for the slurring. But now we have explained why the pragmatic explanation, despite being parasitic on Lepore and Anderson's rule of use, does more work than the original explanation by Lepore and Anderson. Thus, it could be recommended by Modified Occam's Razor, because even if Lepore and Anderson's view appears to be simpler, it cannot explain what the conversational implicature view-which is more complex-does explain.

Objection. Why should the reporter have to use some form of substitution of the slurring in question, if after all the devices of quoting and of mix-quoting in indirect reports allow her to avoid responsibility, since after all quoting does not amount to using a certain expression. The reply is simple. It is true that the reporter is not using the slurring in question and, therefore, cannot be accused of having used a slurring word. However, in depicting the slurring, rather than describing it by a suitable transformation and by some descriptive phrase alluding to the

21 This position is somewhat reminiscent of Seymour's (1994) treatment of in direct reports, in which reference to a translation of the reported sentence is explicitly incorporated in the semantics of in direct reports.

22 It is difficult to suggest which alternative is more neutral than a slurring term. Baugh (1991) frankly points out that Americans find it difficult to find a term which is not insulting or less insulting that 'negro'. The term 'black' used to be offensive in the past, but no longer is. The term 'coloured' used to be acceptable in the past but is now offensive. Presumably the least connotative is 'African American' a term which the Reverend Jesse Jackson managed to introduce into American's public life. However, as Du Bois (1928) stresses, if hatred and despise target a certain social group, then it will survive despite the fact that new names replaced the old ones associated with negative connotations. However, I want to point out that the term 'African American' is destined to be successful because it avoids all reference to the color of the skin. So, ideologically, it is much better than many other names. It voices the desire NOT to be classified by color and a rejection of the old stereotype that people should be classified by color. 
slurring character of the original phrase, the reporter is signalling some complicity since she is not distancing herself from the trespasser (the original speaker). Since using depictive elements involves taking the shortest route in the description process, when there is an alternative route which by embarking on a transformation involves greater processing efforts (and production efforts), it is clear that the avoidance of greater processing costs is taken as a sign of complicity, while the more costly transformation is taken (or would be taken) as a way of signalling that one is distancing oneself from the offensive segment of talk. We could consider 'complicity' a language game, in which two voices blend in case they share the same point of view. While in the normal case in which two speakers have different points of view, they tend to differentiate their voices, in the case of complicity two voices are presented as undifferentiated. Indirect reports are prototypical cases in which an utterance gives expression to two voices, the original speaker and the reporter. Thus, it goes without saying that an indirect report should present two slots in case the original speaker's voice and the reporter's voice are differentiated and only one slot in case the two voices blend (being undifferentiated). The presence of just one slot, instead of two slots clearly exhibits the complicity between the two voices. Of course, readers may ask, how can we have two or just one slot for voices in indirect reports? Is this a semantic or a pragmatic matter? The natural answer is that the slots are provided pragmatically and should be considered not as distinct syntactic positions but as portions of text where we can reveal implicit quotation marks. It is the rich structure of cues and clues which will point towards two or, rather, one slot capable of expressing point of view.

\section{Conclusion}

In this chapter, I have deepened my view that indirect reports are cases of language games. I have mainly explored the analogies between quotation and indirect reports, and I have maintained that such analogies allow a parallel pragmatic treatment. In the end, I have concentrated on slurring and I have explained why both taboo words and slurring words cannot be embedded in quotation structures without losing their anti-social status. It is clear that slurring too involves the task of separating voices and of accepting the essentially polyphonic structure of discourse. Essentially the problem, in our case, is how it comes about that when someone reports a slurring expression, there are in fact at least two people-and not just one-doing the slurring. This is a complicated but interesting question, which puts to the test both the theory of quotation and that of indirect reports, throwing light on parallel problems about polyphony and the way it is supported by conversational implicature. 


\section{References}

Baldwin, T. (1982). Prior and Davidson on indirect reports. Philosophical Studies, 42(2), 255-282.

Baugh, J. (1991). The politicization of changing terms of self-reference among American slave descendants. American Speech, 66(2), 133-146.

Burton-Roberts, N. (2006). Cancellation and intention. Newcastle University, School of English, Mn. Published in the Newcastle working papers in linguistics. In E. Romero \& B. Soria (Eds.), Explicit communication: Robyn Carston's pragmatics (2010) (pp. 138-155). London: Palgrave-Macmillan.

Capone, A. (2008). Belief reports and pragmatic intrusion: The case of null appositives. Journal of Pragmatics, 40, 1019-1040.

Capone, A. (2009). Are explicatures cancellable? Toward a theory of the speaker's intentionality. Intercultural Pragmatics, 6(1), 55-83.

Capone, A. (2010a). On the social practice of indirect reports (further advances in the theory of pragmemes). Journal of Pragmatics, 42, 377-391.

Capone, A. (2010b). What can modularity of mind tell us about the semantics/pragmatics debate. Australian Journal of Linguistics, 30(4), 497-520.

Capone, A. (2012). Indirect reports as language games. Pragmatics and Cognition, 20(3), 593-613.

Capone, A. (2013). The pragmatics of quotation. Pragmatics and Society, 4(3), 259-284

Cappelen, H., \& Lepore, E. (2005a). Insensitive semantics: A defence of semantic minimalism and speech act pluralism. Oxford: Blackwell.

Cappelen, H., \& Lepore, E. (2005b). Varieties of quotation revisited. Belgian Journal of Philosophy, 17, 51-76.

Carston, R. (2002). Thoughts and utterances. The pragmatics of explicit communication. Oxford: Blackwell.

Clark, H. H., \& Gerrig, R. J. (1990). Quotations as demonstrations. Language, 66(4), 764-805.

Dascal, M., \& Weizman, E. (1987). Contextual exploitation of interpretation clues in text understanding: An integrated model. In J. Verschueren \& M. Bertuccelli-Papi (Eds.), The pragmatic perspective (pp. 31-46). Amsterdam: John Benjamins.

Dascal, M., Hintikka, J., \& Lorenz, K. (1996). Games in language. In M. Dascal, D. Gerhardus \& K. Lorenz (Eds.), Sprachphilosophie (vol. II, pp. 1371-1392). Mouton De Gruyter.

Davidson, D. (1968). On saying that. Synthese, 19, 130-146.

De Rose, K. (2009). The case for contextualism. Oxford: OUP.

Douven, I. (2010). The pragmatics of belief. Journal of Pragmatics, 42, 35-47.

Du Bois, W. E. B. (1928). The name 'Negro'. The Crisis, 35, 96-97.

Goffman, E. (1974). Frame analysis. New York: Harper \& Row.

Goffman, E. (1981). Forms of talk. Philadelphia: University of Pennsylvania Press.

Kennedy, R. (2002). 'Nigger': The strange career of a troublesome word. New York: Pantheon. Lepore, E., Anderson, L. (2013). Slurring words. Noûs, 47(1), 25-48.

Levinson, S. (1983). Pragmatics. Cambridge: CUP.

Lyons, J. (1977). Semantics, 1-2. Cambridge: CUP.

Potts, C. (2005). The logic of conventional implicatures. Cambridge: CUP.

Recanati, F. (2010). Truth-conditional pragmatics. Oxford: Oxford University Press.

Rumfitt, I. (1993). Content and context: The paratactic theory revisited and revised. Mind, 102(407), 429-454.

Saka, P. (1998). Quotation and the use-mention distinction. Mind, 107(425), 113-135.

Seymour, M. (1994). Indirect discourse and quotation. Philosophical Studies, 74(1), 1-38.

Simons, M. (2013). Mandy Simons, on the conversational basis of some presuppositions. In A. Capone, F. Lo Piparo \& M. Carapezza (Eds.), Perspectives on pragmatics and philosophy. Dordrecht: Springer. 
Sperber, D., Wilson, D. (1986). Relevance theory. Oxford: Blackwell. Reprinted with postface in 1995.

Tannen, D. (1989). Talking voices. Repetition, dialogue, and imagery in conversational discourse. Cambridge: CUP.

Vološinov, V. N. (1971). Reported speech. In L. Matejka \& K. Pomorsko (Eds.), Readings in Russian poetics (pp. 149-175). Cambridge, Mass.: MIT Press.

Wieland, N. (2010). Minimal propositions and real world utterances. Philosophical Studies, 148, 401-412.

Wieland, N. (2013). Indirect reports and pragmatics. In A. Capone, F. Piparo \& M. Carapezza (Eds.), Perspectives on pragmatics and Philosophy. Dordrecht: Springer.

Williamson, T. (2007). Reference, inference and the semantics of pejoratives. In J. Almog \& P. Leonardi (Eds.), Festschrift for David Kaplan. Oxford: OUP.

Wittgenstein, L. (1953). Philosophical investigations. Oxford: Blackwell. 